\title{
Illustrated Review of the Embryology and Development of the Facial Region, Part 1: Early Face and Lateral Nasal Cavities
}

P.M. Som and T.P. Naidich

\section{ABSTRACT}

SUMMARY: The early embryological development of the face has been reviewed. One repeating theme to note is the serial closing and then the re-opening of a space. This is seen in the separation of the nasal and oral cavities, the nostrils, and in part 2 the developing eyelids fusing and then re-opening. Part 2 will discuss the further facial development as well as the changes in facial bone appearance after birth.

K nowledge of the embryology of the facial region not only allows one insight into how normal variations in facial structure arise but also provides an understanding of how congenital deformities occur when normal facial development goes awry. This embryology can be considered as an anatomic series of complex, well-orchestrated changes in morphology or as a series of complex biochemical events that actually orchestrate the anatomic changes. The scope of this review (Part 1) is to present the current understanding of the early morphologic formation of the normal face. It will be presented in a highly illustrated format so that the reader can better understand how the normal facial region comes into being. Because many different areas develop virtually at the same time, we will present the embryology with a focus on regional development, making every attempt to clarify the sequential overlapping changes that occur. In addition, how the facial morphology changes during the transition from late fetal development to childhood and then to adulthood will be discussed in Part 2. Because the subject is complex, the literature reflects uncertainty about the timing of specific events and even the true nature of the events themselves. In this review, we present the prevalent interpretations in the literature. ${ }^{1,2}$ Part 3 will address the molecular changes that coordinate and control the morphologic development.

\section{Overall Perspective: Where the Cells Come From}

The major development of the facial region occurs between the fourth and eighth embryonic weeks via a series of highly coordinated and preprogrammed events. This process includes contribu-

From the Department of Radiology, Mount Sinai School of Medicine, New York University, New York, New York.

Please address correspondence to Peter M. Som, MD, Department of Radiology, The Mount Sinai Hospital, One Gustave Levy Place, New York, NY 10029; e-mail: Peter.Som@MSSM.edu

- Indicates open access to non-subscribers at www.ajnr.org

http://dx.doi.org/10.3174/ajnr.A3415 tions from the head ectoderm, which will help form the face and oral cavity, and the neural crest mesenchyme, which contributes to the first branchial arch and its derivatives. This mesenchyme is derived from the neural crest and prechordal plate. It appears that the future frontonasal region has mesenchyme from 2 origins of neural crest cells. The midbrain neural crest cells migrate between the area of the future lens placode and the optic cup to reach the frontonasal region, just beneath the nasal placode region where they form the lateral nasal process. The forebrain neural crest cells appear destined to form the medial nasal processes (Figs 1 and 2). ${ }^{3}$

\section{Beginning}

Shortly after the anterior neuropore closes in the late third to early fourth week, the forebrain enlarges and pushes the overlying ectoderm forward and laterally, creating the frontonasal process (Fig 3). The enlarging brain and frontonasal process contribute to an ectodermally covered invagination, the stomodeum, which develops below them in the early fourth week. The ectoderm over the stomodeum comes to abut the endoderm of the developing foregut to form the oropharyngeal membrane. In the fifth week, the oropharyngeal membrane disintegrates, creating communication between the foregut and the outside (Fig 2). At the same time, mesenchymal growth in the first branchial arch produces first the maxillary process and then the faster growing mandibular process on each side of the future face. The mandibular processes rapidly extend to the facial midline and merge. The stomodeum is now surrounded by the frontonasal process above, the paired maxillary processes on either side, and the paired mandibular processes below (future lower jaw) (Fig 3). ${ }^{1,2}$

\section{Nasal (Olfactory) Placodes}

The sensory placodes arise from a common "preplacodal field" at the anterior neural crest border. ${ }^{4}$ They then differentiate to eventually have individual developmental fates (this topic is more extensively 


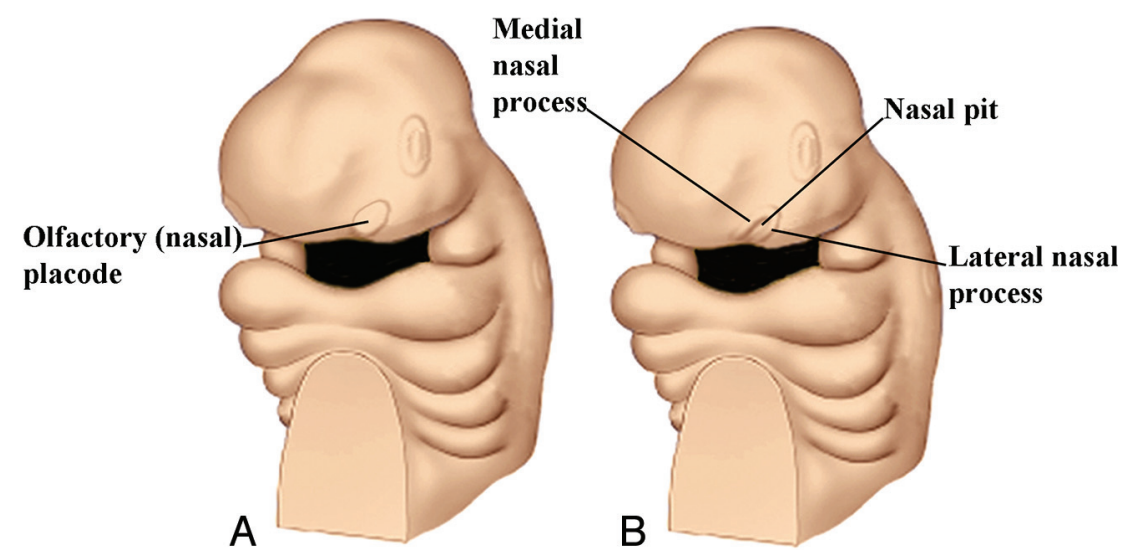

FIG 1. Anterior oblique drawing $(A)$ of a 5 -week embryo showing the appearance of the nasal (olfactory) placode. $B$, Drawing shows the development of the medial and lateral nasal processes forming a downward-facing "horseshoe" around the sinking nasal placode, which forms the nasal pit.
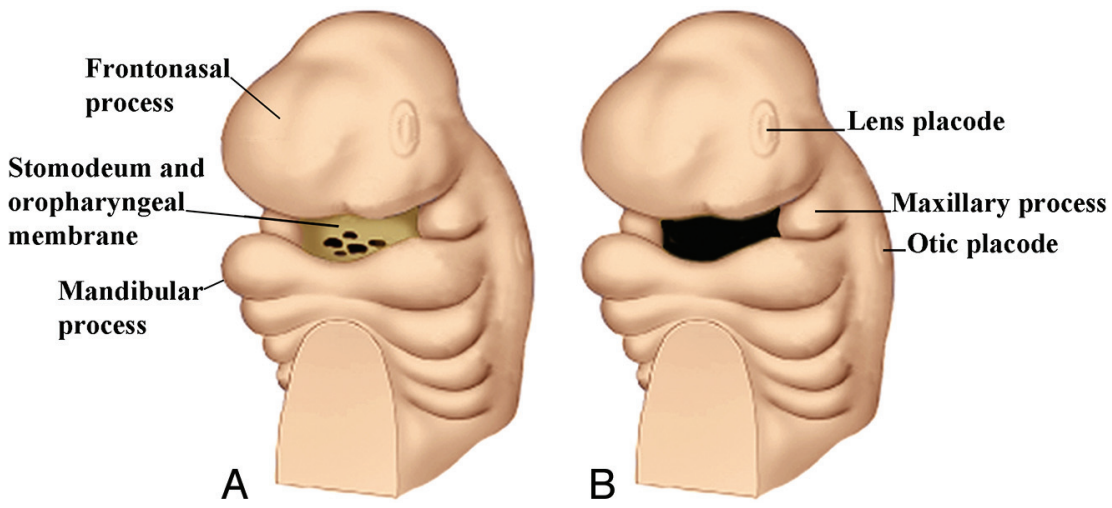

FIG 2. Anterior oblique drawing of an embryo in the late fourth week $(A)$ shows the stomodeum with the oropharyngeal membrane surrounded by the further development of the frontonasal process and the maxillary and mandibular processes. $B$, Drawing shows the breakdown of the oropharyngeal membrane by the fifth week. The early appearance of the lens and otic placodes is also seen.
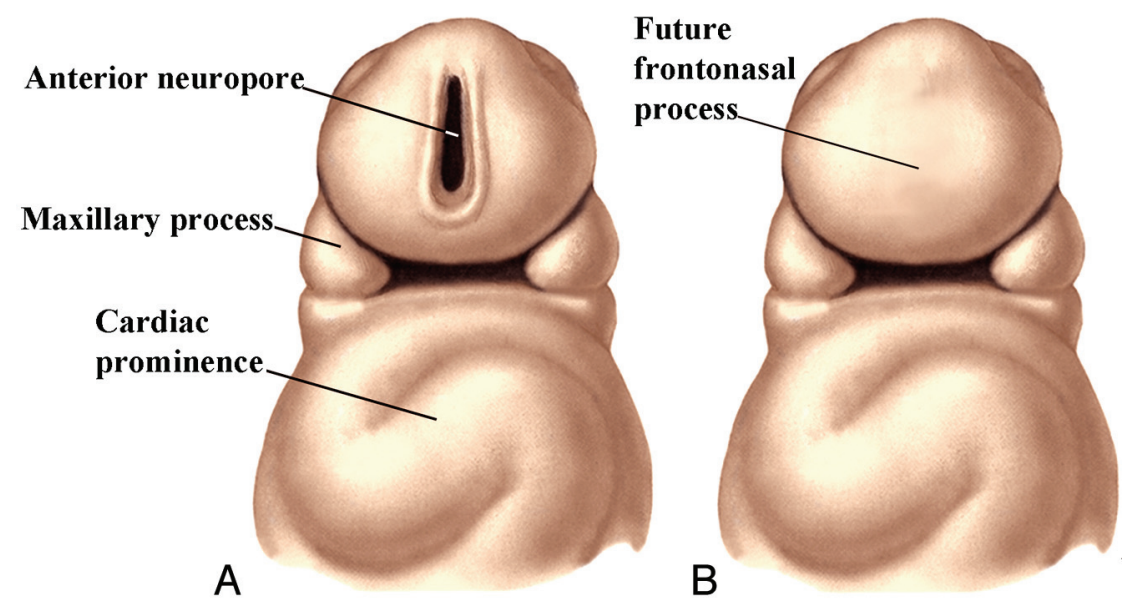

FIG 3. Drawing $(A)$ of a ventral view of a 3- to 4-week embryo shows the anterior neuropore and the early formation of the maxillary processes. Drawing $(B)$ in the late fourth week shows closure of the anterior neuropore and the location of the future frontonasal process. (Modified with permission from Netter's Atlas of Human Embryology. Edited by Cochard, L.R., PhD. 2002. Icon Learning Systems, Teterboro, New Jersey, Figures 9.5. Netter Illustrations from www.netterimages.com, $\odot$ Elsevier Inc, All rights reserved).

discussed in Part 3). These placodes are ectodermal thickenings that arise through cell division during neural tube formation (Fig $2 A$ ). By the end of the fourth week, the nasal placodes (or olfactory placodes) develop as well-defined epiblastic thickenings of 2-3 cell layers on either side of the frontonasal process (Fig 1A). Each nasal placode begins to deepen as a result of a combination of active growth of the placodal epithelium and a proliferation of the mesenchyme deep to the edges of the placode. As each nasal placode starts to sink below the surface as a nasal groove, first the lateral nasal process develops in the early fifth week; then the medial nasal process develops shortly there- 

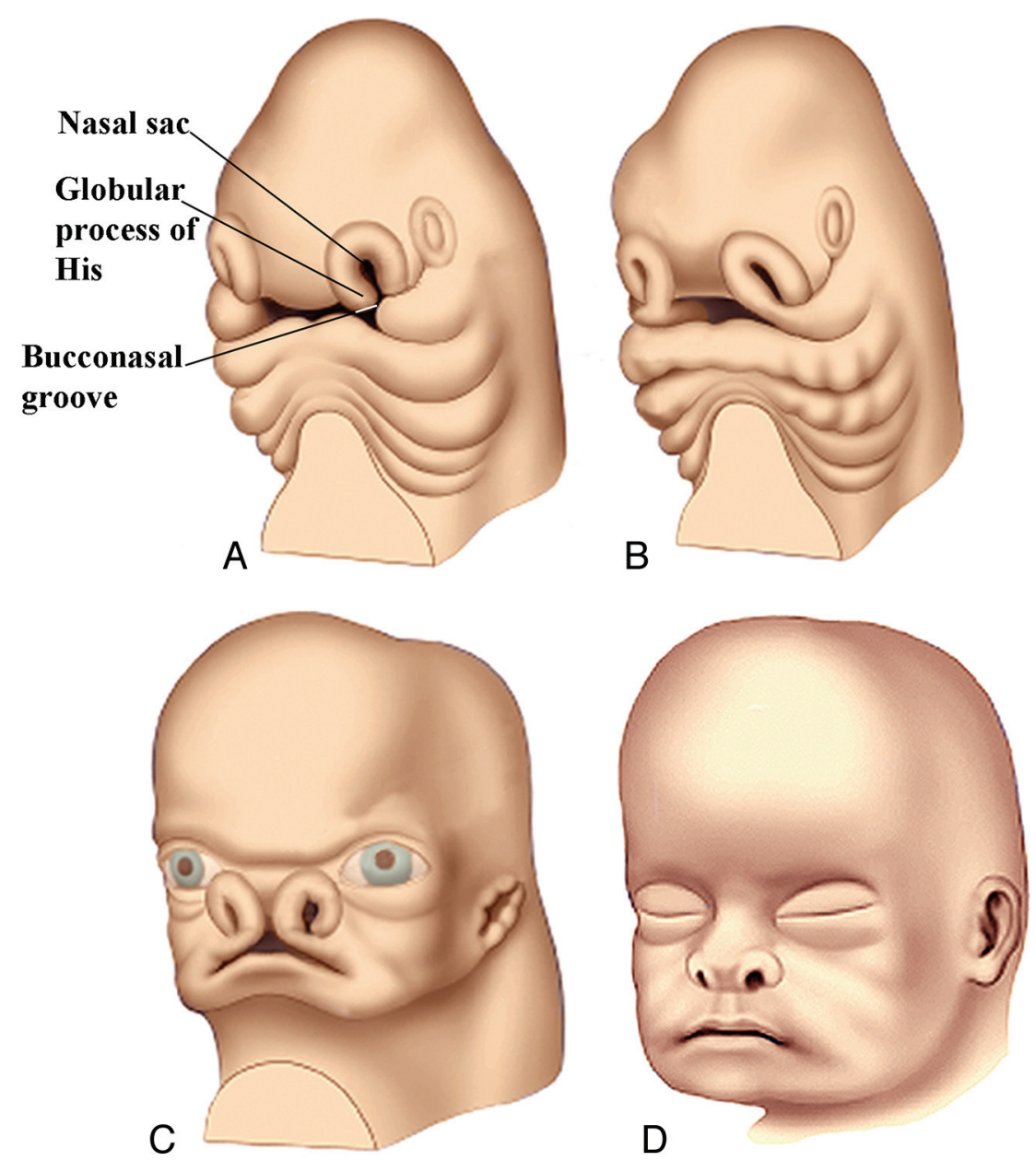

FIG 4. Anterior oblique drawing of a 5 -week embryo $(A)$ shows the further growth of the medial and lateral nasal processes and the development of the nasal sac. The bucconasal groove is shown. $B$, Anterior oblique drawing of a 6-week embryo shows closure of bucconasal groove completing the floor of the nasal cavity and progressive flattening of the nasal sac openings, mainly as a result of ventrolateral growth of the medial nasal processes. The nasal sacs are also pushed toward the midline as the maxillary processes grow. Anterior oblique drawing of a 7-week embryo (C) and a 10-week (D) embryo shows the progressive medial movement of the nasal sacs and the resulting progressive pushing upwards of the frontonasal process.
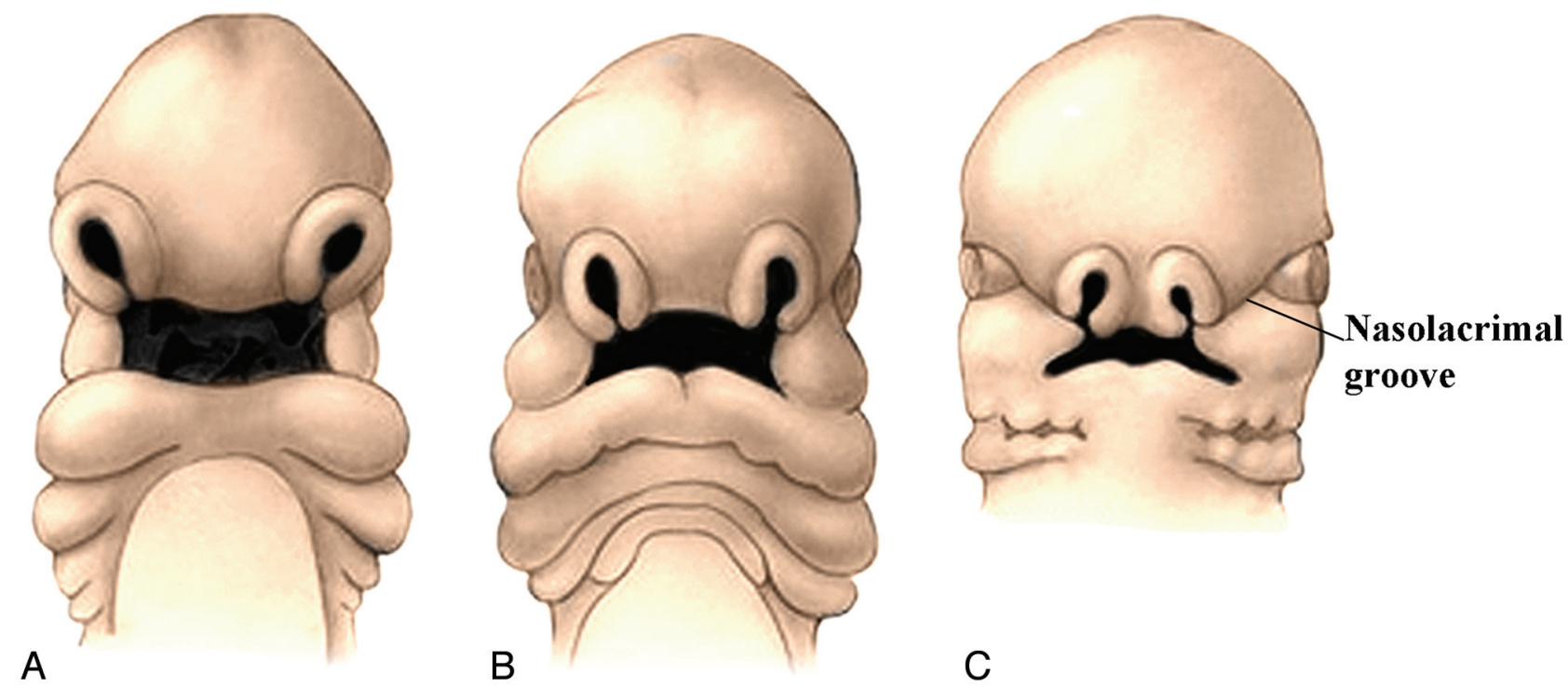

FIG 5. Frontal drawings of 4- to 5-week $(A)$ and 5- to 6-week $(B)$ embryos illustrate the progressive displacement of the nasal sacs toward the midline as a result of medial growth of the maxillary processes. Frontal view of a 6- to 7-week embryo $(C)$ shows the nasolacrimal groove. Closure of this groove establishes continuity between the side of the nose formed by the lateral nasal process and the cheek formed by the maxillary process. (Modified with permission from Levine HL, Clemente MP, eds. Chapter 1, Surgical Anatomy of the Paranasal Sinus. China: 2005. Sinus Surgery Endoscopic and Microscopic Approaches. Figures 1-2. Thieme Medical Publishers Inc., Georg Thieme Verlag Stuttgart). 


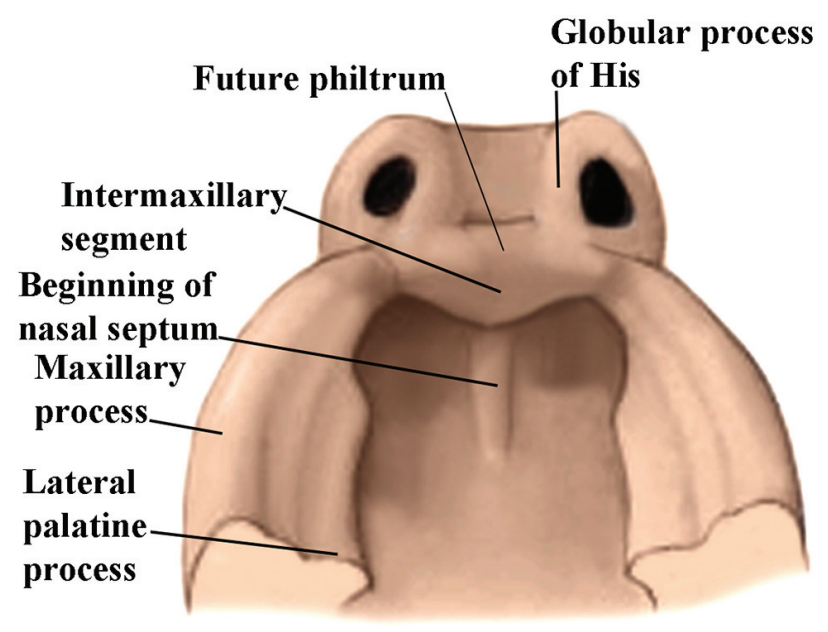

FIG 6. Drawing from below of a 6-week fetus showing the emergence of the intermaxillary segment below the medial nasal processes. This segment may actually arise from the globular processes of His. Also shown is the maxillary process and, arising from its medial surface, the lateral palatine process, which will form the secondary palate. (Modified with permission from Levine HL, Clemente MP, eds. Chapter 1, Surgical Anatomy of the Paranasal Sinus. China: 2005. Sinus Surgery Endoscopic and Microscopic Approaches. Figures 1-3. Thieme Medical Publishers Inc., Georg Thieme Verlag Stuttgart).

after. Together they form a downward-facing "horseshoe" with the open end facing the stomodeum (Fig 3). As the medial and lateral nasal processes develop and become more prominent, the nasal grooves deepen and become the nasal pits. By the late fifth week, these pits continue to actively deepen and are thrust back into the stomodeum, forming the nasal sacs (Fig 4). The medial nasal process is more prominent than the lateral nasal process, extending farther ventrally and caudally. Each medial nasal process has an enlarged caudal end that is called the "globular process of His " (Fig 4A). ${ }^{1,5}$

\section{Olfactory Epithelium and Nerves}

During the early fifth week, the ectoderm in the upper one-third of each enlarging nasal sac becomes thickened and develops into the olfactory epithelium. Some cells will become spindle-shaped olfactory cells, while others will become supporting cells and basal cells. The neural epithelium facing the olfactory epithelium becomes thickened with strands of cells oriented toward the olfactory epithelium. By 5 weeks, the olfactory epithelium develops cellular buds and an associated vascular network as well as cells penetrating the basement membrane. These sensory epithelia send out nerve processes that form arborescences around the neural cells of the outgrowing olfactory lobe on each side. These will form the olfactory nerves. By late in the fifth week, a continuous cellular/vascular strand appears between each nasal sac and the olfactory field of the telencephalon. ${ }^{5}$ By the late seventh week, the olfactory epithelium is confined to its "adult" location on the upper lateral nasal wall and the nasal septum. ${ }^{1}$

\section{Midfacial Development}

During the fifth week, while the olfactory portions of the nasal sacs are developing, the maxillary processes grow medially. This medial growth results in medial displacement of the nasal sacs (Figs 4 and 5). At the same time, there is also some ventrolateral expansion of each medial nasal process, which causes compres-
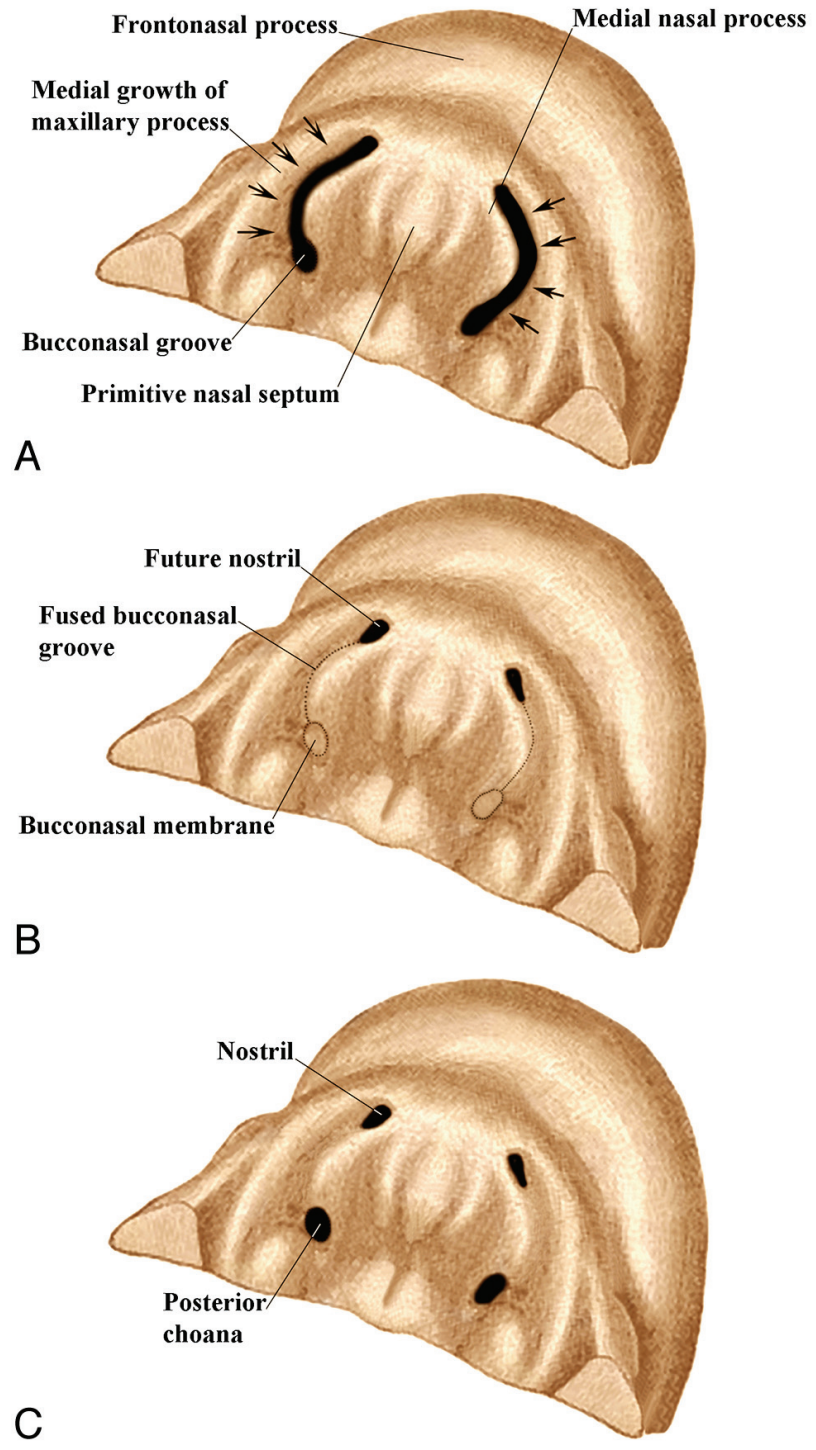

FIG 7. Drawings of the inferior view of an embryo from the sixth $(A)$ to seventh weeks $(C)$ show the bucconasal groove starting to close because of medial growth of the maxillary processes $(A)$. $B$, There is fusion along most of the course of the bucconasal groove and membranous closure posteriorly by the bucconasal membrane. $C$, The oronasal membrane (thinned bucconasal membrane) has ruptured, creating an opening for communication between the primitive nasal and oral cavities (posterior choana).

sion of each nasal sac aperture into a slit-shaped opening (Fig 4B). In the sixth week, the medial aspects of the 2 medial nasal processes form a thickened mesodermal region anteriorly beneath and between the early nasal sacs. This constitutes the intermaxillary segment, and it may actually be formed by the joining of the globular processes of His (Fig 6). This will be discussed further when the development of the palate is discussed in Part 2. ${ }^{1,2}$

\section{Closing Off the Nasal Cavity}

On each side of the developing face, the bucconasal groove is the groove between the maxillary process and the medial nasal process (Fig 4A). Fusion across this groove occurs in the fifth week as a result of medial growth of the maxillary process (Fig 7). Anteriorly, the fusion of the medial nasal and maxillary processes forms 

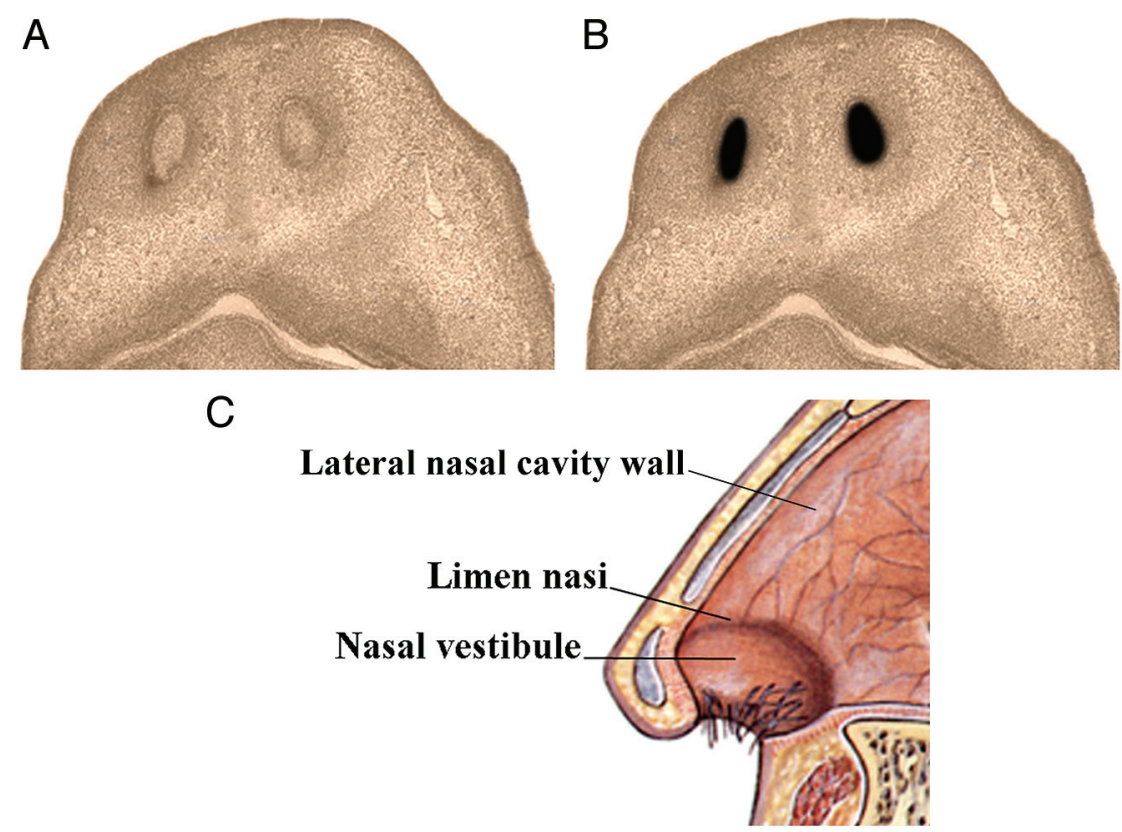

FIG 8. Drawings from below of a 7-week embryo $(A)$ and a 13- to 15 -week fetus $(B)$ show epithelial plugs closing the nostrils $(A)$ and then dissolving (B). If a plug does not dissolve, there will be atresia of the nostril. Lateral drawing of the anterior nose (C) shows the nasal vestibule and limen nasi. These areas mark the location of the nasal epithelial plugs.
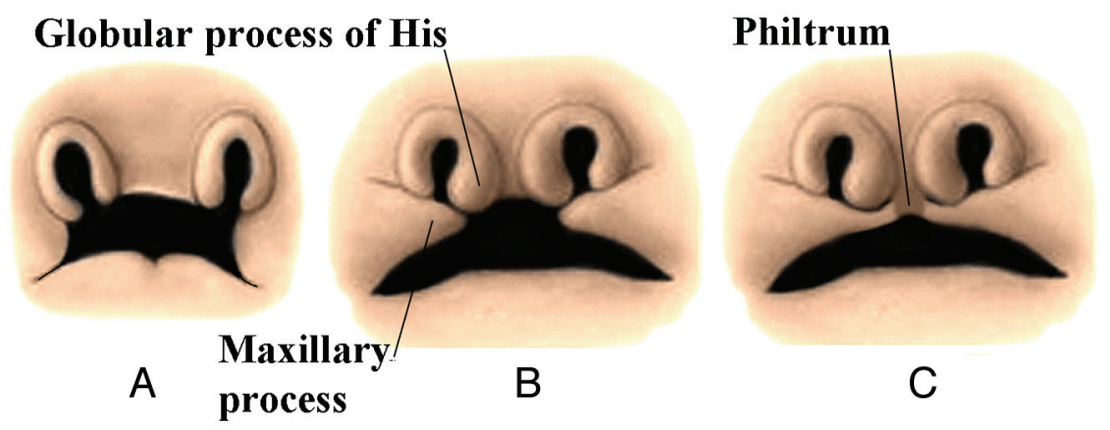

FIG 9. Frontal drawings of the upper lip region in embryos at $5(A), 6(B)$ and $7(C)$ weeks show the progressive medial growth of the maxillary processes toward the midline. However, the actual midline of the upper lip (the philtrum) is formed by the medial nasal processes. (Modified with permission from Levine HL, Clemente MP, eds. Chapter 1, Surgical Anatomy of the Paranasal Sinus. China: 2005. Sinus Surgery Endoscopic and Microscopic Approaches. Figures 1-3. Thieme Medical Publishers Inc., Georg Thieme Verlag Stuttgart).

the lower nostril region (Fig $4 B,-C$ ). More posteriorly adjacent to the intermaxillary segment, the fusion across this bucconasal groove closes the floor of the nasal sac. At the most posterior margin of the groove, the closure across the bucconasal groove is not by fusion but by the growth of an epithelial membrane, the bucconasal membrane. The overall fusion across the bucconasal groove is often referred to as the nasal fin, and it separates the primitive nasal cavity from the primitive oral cavity. Before the closure of the bucconasal groove, the primitive nasal cavity and oral cavity were a common cavity. The dorsal epithelial membrane quickly begins to thin, and by the sixth week, it is just a 2-layered epithelium called the oronasal membrane. By the midsixth week, the oronasal membrane ruptures to form the primitive posterior choana. With the dissolution of the oronasal membrane, the primitive nasal cavity and posterior primitive oral cavity once more freely communicate (Fig 7). They will eventually again be separated by the development of the palate. Anteriorly the future nostril is complete and separated from the developing oral cavity. Thus, by the seventh week, each nasal cavity opens to the outside through a nostril and communicates posteriorly with the pharynx via the primitive choana. If the oronasal membrane is not ruptured, the posterior choana is obstructed and congenital choanal atresia develops. ${ }^{1,2}$

\section{Nasal Plugs}

Paralleling these changes, a broadening of the head occurs behind the nasal pits, resulting in a shifting of the nasal pits from a lateral to a more ventromedial location, approaching the midline (Fig 5). By the mid-seventh week, the anterior lumen of each primitive nasal cavity becomes tightly filled by a proliferation of epithelial cells that form an epithelial plug (Fig 8A). By the 13th to 15th week, this plug dissolves, and by the mid-16th week, the nasal passages are complete and open (Fig $8 B$ ). The region occupied by the plug will become the nasal vestibule and the future limen 

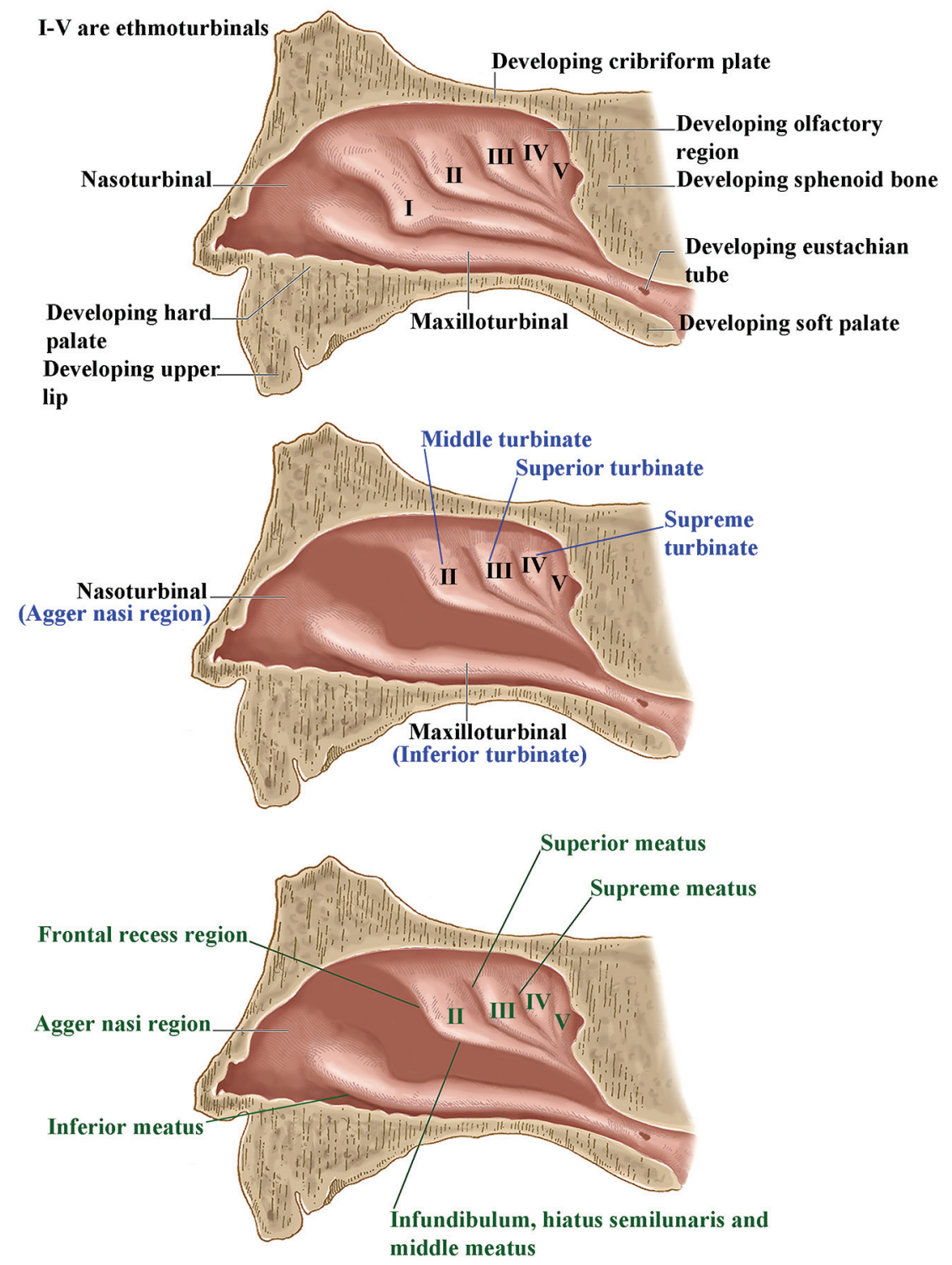

FIG 10. Lateral drawings of the developing lateral nasal wall showing the appearance of the nasal turbinals and their eventual development into the nasal turbinates and meati.

nasi, which is a ridge separating the nasal cavity proper from the vestibule of the nose (Fig $8 C$ ). As a consequence, the nasal vestibule consists of skin and adnexa derived from ectoderm. If this epithelial plug does not disintegrate, atresia of the nostril will occur. ${ }^{6}$

\section{Forming the Upper Lip}

Ventrally, the fusion of the medial nasal processes with the maxillary processes will form most of the upper lip and upper jaw on both sides. The 2 merged medial nasal processes then form the philtrum and columella and complete the upper lip (Fig 9). The fusion of the 2 medial nasal processes displaces the frontonasal process superiorly and posteriorly (Figs $4 C$ and $5 C$ ). As a result, although the frontonasal process formed the upper border of the stomodeum, it does not contribute to the definitive upper lip, jaw, or nasal tip. The medial migration of the maxillary processes forms not only the lateral upper lip but the upper cheek regions, resulting in continuity of the upper jaw and lip (Fig 4D). ${ }^{1,2}$

\section{Lateral Nose and Nasolacrimal Duct}

By the end of the sixth week, the lateral nasal processes begin to merge with the maxillary processes to form the ala nasi or lateral nose and the lateral border of the nostril on both sides (Fig 4D). On each side of the face, along the junction between the maxillary and lateral nasal processes is the nasolacrimal groove (naso-optic furrow) (Fig 5C). The nasolacrimal groove extends between the developing lower lateral nose and the medial orbit. The ectoderm along the floor of each groove thickens to form a solid epithelial cord, which then detaches from the groove and canalizes to form the nasolacrimal duct and lacrimal sac. By the late fetal period, the nasolacrimal duct on each side extends from the medial corner of the orbit to the inferior meatus in the lateral wall of the nasal cavity. These ducts usually become completely patent only after birth. Closure of the nasolacrimal groove establishes continuity between the side of the nose formed by the lateral nasal process and the cheek formed by the maxillary process. ${ }^{1,2}$ 


\begin{tabular}{|c|c|}
\hline Late 3 rd to early 4 th & Anterior neuropore closes; oropharyngeal membrane appears \\
\hline Early 4th & Frontonasal process appears; early development of maxillary and mandibular processes creates stomodeum \\
\hline Late 4th & Oropharyngeal membrane disintegrates; nasal (olfactory) placodes appear \\
\hline Early 5th & $\begin{array}{l}\text { Lateral nasal processes and then the medial nasal processes appear, forming nasal pit; mandibular processes } \\
\text { meet in midline; olfactory epithelium starts to form in upper nasal cavities }\end{array}$ \\
\hline Late 5th & $\begin{array}{l}\text { Nasal sacs form; medial nasal processes fuse with maxillary processes and form nasal fins, separating primitive } \\
\text { nasal and oral cavities; nasal sacs migrate more medially and become more slit-like; olfactory nerves form; } \\
\text { Meckel cartilage forms }\end{array}$ \\
\hline Early 6th & $\begin{array}{l}\text { Oronasal membrane forms and disintegrates opening posterior nasal choana; medial nasal processes start to } \\
\text { form primitive nasal septum and primary palate }\end{array}$ \\
\hline Late 6th & $\begin{array}{l}\text { Lateral palatine processes develop; they are initially directed caudally alongside and above the tongue; naso- } \\
\text { optic furrow develops and nasolacrimal duct forms (will become patent at birth); external ear develops; } \\
\text { labiogingival laminae appear; lips and gums separate; dental lamina appears; maxilloturbinal (future inferior } \\
\text { turbinate) starts to form; remaining nasal turbinals form; eyelids start to form }\end{array}$ \\
\hline Early 7 th & $\begin{array}{l}\text { Philtrum and upper lip complete; nasal septum further develops; external olfactory epithelium confined to } \\
\text { upper nasal cavities and further develops }\end{array}$ \\
\hline Late 7th & $\begin{array}{l}\text { External ear fully developed; nasal plugs close nostrils (will open again in 16th week); cartilaginous nasal capsule } \\
\text { develops; palatal shelves elevate and fuse, forming secondary palate; future nostril now complete; eyes move } \\
\text { more to midline; fusion of maxillary and mandibular processes narrows the width of the mouth and } \\
\text { completes lower cheeks }\end{array}$ \\
\hline 8th & Lateral nasal wall well-developed; facial muscle primordia appear (muscles develop by 9th week) \\
\hline 9th-10th & Nasal septum starts to fuse with palate (will be complete by 12th week); ossification of maxillas occurs \\
\hline 10th-11th & $\begin{array}{l}\text { Uncinate process arises; infundibulum then develops; tooth buds become cup-shaped (teeth will be near } \\
\text { complete in 6th month); eyelids fuse (will open in 26th-28th weeks) }\end{array}$ \\
\hline 12th & Ossification centers of all facial bones are present \\
\hline
\end{tabular}

a The timeline of development differs slightly in the references quoted in Parts 1 and 2 of these articles. The timeline in this Table represents a compilation of the various dates in these references, and because some normal variation is to be expected, this Table represents the best averaging of any differences in developmental dates that we could make.

\section{Nasal Septum and Turbinates}

The last part of the chondrocranium to become cartilaginous is the nasal capsule. Condensation of the mesenchyme within the frontonasal process forms the precartilaginous nasal septum in the upper midline of the primitive nasal cavity (Fig 6). Cartilage from the body of the developing sphenoid bone then extends forward into the nasal septum, forming the primary cartilage of the nasal septum by the mid-sixth week. The roof of the capsule is formed by the coalescence of cartilage from the nasal septum and from extensions of cartilage from the ventral surface of the sphenoid and secondary centers in the lateral wall of the capsule. The cartilage is at first open on either side of the nasal septum to allow passage of the olfactory fasciculi. During the third month, cartilage fills in the capsule around these nerves, forming the cribriform plates. Lateral strips of cartilage then extend back to unite with the face of the sphenoid.

The cartilaginous nasal capsule develops as 2 separate masses around the forming nasal cavities and the developing nasal septum. While the median mass will become the progenitor of the nasal septum, the lateral masses will become the lateral nasal wall structures. By the third month, the nasal capsule is well-defined cartilage.

All of the turbinates and the paranasal sinuses arise from the cartilaginous nasal capsule. Several soft-tissue folds appear on the lateral wall of each nasal cavity, the preturbinals, which are first supported by cartilage and then by bone. The maxilloturbinal develops first and then is followed by 5 ethmoturbinals (in men, the first ethmoturbinal disappears). An additional rudimentary nasoturbinal arises anteriorly, appearing later as a slight elevation, the agger nasi (Fig 10). By the eighth week, the inferior and middle turbinate anlagen forms, followed by the superior turbinate anlagen. They develop by proliferation of mesenchymal cells and hypertrophy of the overlying epithelium. During the seventh month, the maxilloturbinal separates from the lateral wall and becomes an independent bone in the adult.

By the eighth week, the lateral nasal wall is well-developed. The length of the lower 3 turbinates increases progressively and proportionally in uterine life, while the supreme turbinate remains at an average length of $5 \mathrm{~mm}$ from the 14th to 36th week and is present in only $65 \%$ of fetuses. The outpouchings of the nasal mucous membranes that will become the paranasal sinuses are thought to be a secondary phenomenon rather than a primary force in sinonasal development. ${ }^{7,8}$

The uncinate process arises from the cartilaginous capsule at 10 weeks. An air channel then progressively develops lateral to the uncinate process. This will be the primitive infundibulum by 10-11 weeks. The embryonic woven bone of the maxilla can be seen between 9 and 10 weeks, and it then enlarges relative to the nasal cavity. By 13-14 weeks, the expanding maxilla now forms the lateral wall of the inferior meatus as the cartilaginous capsule regresses. ${ }^{9}$ By the 16 th week, the primitive maxillary sinus starts to develop from the inferior margin of the infundibulum. ${ }^{10}$

In order to be concise and for future reference for Part 2, the Table summarizes the morphologic changes described in both Parts 1 and 2 of these reviews. One repeating theme is the serial closing and then the reopening of a space. This is seen in the separation of the nasal and oral cavities, the nostrils, and the developing eyelids fusing and then reopening in Part 2.

\section{REFERENCES}

1. Kim CH, Park HW, Kim K, et al. Early development of the nose in human embryos: a stereomicroscopic and histologic analysis. $\mathrm{La}$ ryngoscope 2004;114:1791-800

2. Warbrick JG. The early development of the nasal cavity and upper lip in the human embryo. J Anat 1960;94:351-62

AJNR Am J Neuroradiol 34:2233-40 Dec 2013 www.ajnr.org 
3. Osumi-Yamashita N. Retinoic acid and mammalian craniofacial morphogenesis. J Biosci 1996;21:313-27

4. Streit A. The preplacodal region: an ectodermal domain with multipotential progenitors that contribute to sense organs and cranial sensory ganglia. Int J Dev Biol 2007;51:447-61

5. Bossy J. Development of olfactory and related structures in staged human embryos. Anat Embryol (Berl) 1980;161:225-36

6. Nishimura Y. Embryological study of nasal cavity development in human embryos with reference to congenital nostril atresia. Acta Anat (Basel) 1993;147:140-44

7. Levine HL, Clemente MP. Surgical anatomy of the paranasal sinus. In: Levine HL, Clemente MP, eds. Sinus Surgery: Endoscopic and Microscopic Approaches. New York: Thieme; 2005
8. Bolger WE. Anatomy of the paranasal sinuses. In: Kenndy DW, Bolger WE, Zinreich SJ, eds. Diseases of the Sinuses: Diagnosis and Management. Hamilton, Ontario, Canada: B.C. Dekker; 2001:1-11

9. Bingham B, Wang RG, Hawke M, et al. The embryonic development of the lateral nasal wall from 8 to 24 weeks. Laryngoscope 1991;101: 992-97

10. Lee KJ. Essentials of Otolaryngology and Head and Neck Surgery. 8th ed. New York: McGraw Hill; 2003: Chapter 19

11. Cochard LR, ed. Netter's Atlas of Human Embryology. Teterboro, New Jersey; Icon Learning Systems; 2002

12. Netter FL, Craig J, Machado C. netterimages.com. Netter Illustrations. Elsevier. www.netterimages.com. Accessed 2011 